\title{
Parental and romantic attachment systems: neural circuits, genes, and experiential contributions to interpersonal engagement
} James Swain*

Address: Yale Child Study Center, Yale University School of Medicine, USA

* Corresponding author

from International Society on Brain and Behaviour: 2nd International Congress on Brain and Behaviour Thessaloniki, Greece. 17-20 November 2005

Published: 28 February 2006

Annals of General Psychiatry 2006, 5(SuppI I):S3 I doi:I0.II86/I744-859X-5-SI-S3 I4

Intense interpersonal relationships are critical aspects of human life. Important examples are parental and romantic love. Each include a set of highly conserved behaviours and mental states that reflect genetic endowment and the early experience of being cared for as a child, as well as current factors. This paper reviews the neurobiological bases of these states in mammalian species and humans. This includes recent data that suggest that there are critical developmental windows during which the genetically determined microcircuitry of key limbic-hypothalamicmidbrain structures are susceptible to environmental influences that shape human responses to psychosocial stimuli. They may also determine resiliency and vulnerability to various forms of human psychopathology. 